\author{
Marquette University \\ e-Publications@Marquette
}

Clinical Lab Sciences Faculty Research and

Publications

Clinical Lab Sciences, Department of

7-15-2020

\title{
Moving Targets of Bacterial Taxonomy Revision: What Are They and Why Should We Care?
}

Erik Munson

Follow this and additional works at: https://epublications.marquette.edu/clinical_lab_fac

Part of the Laboratory and Basic Science Research Commons 
Marquette University

e-Publications@Marquette

\title{
Department of Clinical Laboratory Science Faculty Research and Publications/College of Health Sciences
}

This paper is NOT THE PUBLISHED VERSION.

Access the published version via the link in the citation below.

Clinical Microbiology Newsletter, Vol. 42, No. 14 (July 15, 2020): 111-120. DOI. This article is @ Elsevier and permission has been granted for this version to appear in e-Publications@Marquette. Elsevier does not grant permission for this article to be further copied/distributed or hosted elsewhere without the express permission from Elsevier.

\section{Moving Targets of Bacterial Taxonomy Revision: What Are They and Why Should We Care?}

\author{
Erik Munson \\ College of Health Sciences, Marquette University, Milwaukee, WI \\ Wisconsin Clinical Laboratory Network Library Technical Advisory Group, Madison, WI
}

\begin{abstract}
Due to the increased widespread use of molecular diagnostics, genome sequencing, and microbiome analysis in microbiology, the field has experienced a massive influx of novel taxa and nomenclature revisions. A subset of these changes is relevant to the clinical microbiology laboratory, particularly in the context of appropriate antimicrobial susceptibility testing and epidemiology of emerging infections. However, assimilation of these changes into daily clinical microbiology laboratory operations can be challenging for a variety of reasons. Recent taxonomic revisions to Enterobacteriaceae, as well as the genera Borrelia, Mycoplasma, and Mycobacterium, are reviewed as examples that illustrate discrepancies between resources of revision data, criticisms of potentially preliminary data, opinions of unnecessary taxonomic revision, and overwhelming data sets for which clinical
\end{abstract}


relevance is difficult to ascertain. Suggestions for implementation of taxonomic revisions are introduced (including references to peer-reviewed biennial taxonomy revision compendia), which could be augmented by a future Clinical and Laboratory Standards Institute guideline.

\section{Introduction}

Both bench-level microbiologists and those in supervisory/directorship roles have borne witness to a massive explosion of microbial nomenclature changes in the past decade. Many of these changes stem from human microbiome studies, particularly those utilizing genome-sequencing techniques that are becoming increasingly accessible to the routine clinical microbiology laboratory. It is therefore assumed that discovery of novel taxa and nomenclature revisions are not likely to cease anytime soon.

Granted, a large proportion of the newly characterized organisms appear to play commensal roles in site-specific ecology, yet some of these taxa may either be of clinical significance in various patient populations or have their significance ascertained with future investigations and peer-reviewed studies. Moreover, the increased utilization of highly accurate identification modalities in the laboratory (e.g., MALDI-TOF [matrix-assisted laser desorption ionization-time of flight]) may lend additional credence to these potential pathogens. With a focus on bacterial organisms, this commentary aims to discuss the relevance of microbial taxonomic revision to clinical microbiology and affiliated disciplines, the means by which taxonomic revisions arise and become publicized, the conundrums associated with these largely moving targets, and potential future means by which laboratorians can make these data relevant and useful to their clinical partners.

\section{Taxonomy Changes and Updates-Why Should We Care?}

Knowledge of microbial taxonomy updates is essential to the practice of the routine clinical microbiology laboratory. As one example, laboratories subscribing to the College of American Pathologists accreditation program have encountered checklist standard MIC.11375 [1], which requires laboratories to assimilate "taxonomic changes that potentially affect the choice of appropriate antimicrobials to report and/or the interpretative breakpoints to use." Reassignment of the former Actinobacillus actinomycetemcomitans to the genus Haemophilus in the mid-1980s [2] allowed Clinical and Laboratory Standards Institute (CLSI) M100 standard-based antimicrobial susceptibility testing of clinically significant isolates utilizing Haemophilus test medium in either disk diffusion or broth microdilution format (with the corresponding variable incubation environments and intervals). The guidelines facilitated the reporting of 9 fluoroquinolone and 15 cephem susceptibility results, in addition to those derived from trimethoprim/sulfamethoxazole, rifampin, tetracycline, ampicillin, macrolide, and $\beta$-lactam/ $\beta$-lactamase inhibitor combination testing.

Subsequent reclassification of the organism into the novel genus Aggregatibacter gen. nov. [3] transitioned CLSI susceptibility testing guidelines to those specific to HACEK group organisms

(Aggregatibacter spp., Cardiobacterium spp., Eikenella corrodens, and Kingella spp.) and located in the CLSI M45 guideline [4]. As a result, such isolates are assayed only on cation-adjusted Mueller-Hinton broth supplemented with lysed horse blood while utilizing broth microdilution. Furthermore, the numbers of reportable fluoroquinolone and cephem agents were reduced to two each. Penicillin and carbapenem susceptibility testing standards were added to the previously mentioned armamentarium. As with this example, microbiologists should be vigilant for taxonomic revisions involving organisms that currently fall into generic CLSI classifications, such as "other non-Enterobacterales" or "Streptococcus viridans group" because amendments to susceptibility testing and reporting practices may be warranted. The reader is additionally directed to the recent CLSI M100 delineation of methicillin resistance testing standards for coagulase-negative Staphylococcus spp.

The accurate identification and reporting of clinically significant bacteria is also important to the epidemiology of emerging pathogens. One example of this paradigm resides within the taxon Elizabethkingia anophelis. This 
Gram-negative bacillus was first isolated in The Gambia from an Anopheles gambiae midgut [5], and 98.6\% and 98.2\% 16S rRNA sequence similarity to Elizabethkingia meningoseptica and Elizabethkingia miricola type strains, respectively, was demonstrated. Initial clinical significance [6] involved a case of neonatal meningitis in Africa, with preliminary biochemical identification as $E$. meningoseptica prior to definitive $E$. anophelis identification via $16 \mathrm{~S}$ rRNA sequencing of the isolate.

On the basis of geographic location and discovery origin, it was originally hypothesized that mosquito vectors were central to E. anophelis disease epidemiology. However, Balm et al. [7] chronicled what was thought to be an E. meningoseptica outbreak in a tertiary Singapore hospital. Follow-up 16S rRNA gene sequencing and wholegenome alignment definitively identified blood and respiratory isolates as E. anophelis [8]. Molecular epidemiology established relatedness between the clinical isolates and isolates derived from sampling of water taps/aerators. Additional genetic determinants were consistent with the clinical course (antimicrobial treatment failure; mortality) in a number of patients. Lau et al. [9] reported three cases of $E$. anophelis sepsis from Hong Kong. Neonatal meningitis was additionally diagnosed in two cases, and the third involved maternal chorioamnionitis. Draft genome sequencing not only confirmed the E. anophelis isolate identity, but also implicated vertical transmission in two cases.

Lau and colleagues [10] expanded clinical and epidemiologic analysis of Elizabethkingia sp. bacteremia to five regional Hong Kong hospitals; $81 \%$ of Elizabethkingia sp. bacteremic episodes were related to E. anophelis, as confirmed by $16 \mathrm{~S}$ rRNA gene sequencing. The mortality rate in these patients was $23.5 \%$ (4/17), while no $E$. meningoseptica bacteremia cases $(n=3)$ were fatal. Increased piperacillin and cotrimoxazole resistance was observed within $E$. anophelis isolates compared to the limited subset of E. meningoseptica. In summary, recognition of current bacterial taxonomy can assist in future epidemiologic and prognostic delineations of Elizabethkingia sp. infections, as well as additional emerging infectious agents.

Finally, reports of novel and revised bacterial taxonomy can potentially be applied to translational research. As an example, the clinical entity of bacterial vaginosis is a dynamic process of dysbiosis in the female lower genital tract. Potter et al. [11] recently performed an in silico analysis of 103 Gardnerella sp. genomes as a means of identifying novel Gardnerella spp. or clarifying existing nomenclature. The authors postulated that a definitive characterization of vaginal microbiome constituents may identify targets for subsequent investigation of disease pathogenesis. Combining multiple phylogenetic tools (one of which is described below) with data analysis that employed conservative adjudication criteria, Potter et al. identified nine Gardnerella genomospecies. In the process, a recent taxonomic designation of Gardnerella piotii sp. nov. [12] was verified, while those of Gardnerella leopoldii sp. nov. and Gardnerella swidsinskii sp. nov. were called into question. Knowledge of intricate bacterial composition could result in future studies that more clearly describe the role that microbes play in certain disease states compared to endogenous host factors.

\section{Genomics-Based Taxonomy Techniques}

Molecular techniques devoted to the genomics-based identification and differentiation of prokaryotes have improved since the advent of DNA-DNA hybridization. Such modalities have included average amino acid identity and tetranucleotide frequency analyses (which have now come to serve as initial screening tools), as well as the discriminatory technique of average nucleotide identity (ANI). Although a $96 \%$ ANI cutoff value over $90 \%$ coverage of the genome of interest is largely espoused in the realm of prokaryotic taxonomy, even this technique possesses some limitations. In a study that contributed to the determination of this parameter, Ciufo et al. [13] identified 335 taxonomic designations for which 10 GenBank (National Center for Biotechnology Information database) assemblies were available with ANI alignments above $10 \%$ coverage. The assemblies were compared to the submitted type taxon assembly and interpreted as concordant (taxonomic agreement) or discordant (taxonomic disagreement). The average ANI for concordant comparisons was $97.1 \%$, while the 
average for discordant comparisons was $86.3 \%$. However, even at the proposed threshold of $96 \%, 77$ concordant pairs with ANI values falling below that threshold were observed (interpreted as false-negative matches), while 9 discordant taxon matches with ANI values exceeding that threshold were observed (interpreted as a failure to confirm the correct species).

Ciufo et al. [13] estimated that two-thirds of genome assemblies residing in GenBank could be confirmed by using ANI methods compared to a type assembly. An additional limitation of this high-discrimination tool is revealed by approximately $4 \%$ of genome assemblies being misidentified and the remaining $30 \%$ being nonevaluable due to a paucity of relevant type strain assemblies. Moreover, an additional moving target involves variable taxon-specific cutoff values. Clearly defined relationships between members of a genus may result in high ANI cutoff values, such as those observed for Mycobacterium bovis, Mycobacterium africanum, and Mycobacterium tuberculosis (approximating 98.8\%). ANI cutoffs of 99.99\% have been established for Streptococcus gibsonii, Streptococcus almquistii, and Streptococcus avellaneus. In contrast, less defined intraspecies relationships can result in lower ANI cutoff values (such as $88.50 \%$ for Stenotrophomonas maltophilia and $93.50 \%$ for Lactobacillus gasseri) [13].

\section{The Code}

Contemporary approaches to the systematic nomenclature of prokaryotes largely had their origin in the plenary session of the First Congress for Bacteriology, held in 1973. The resulting revision of the International Code of Nomenclature of Bacteria (the Code) was published in 1975 [14]. Goals of the document included attempts to simplify the rules of nomenclature (thus encouraging wider use of the Code) and to provide a sound basis for bacterial systematics. The document was subsequently credited for instituting three major reforms in the field of prokaryotic taxonomy. First, it resulted in the creation of the Approved Lists of Bacterial Names that took effect on 1 January 1980. This attempt at standardization established approximately 2,300 valid prokaryotic taxa and removed thousands of useless names. The lists were subsequently published in the International Journal of Systematic Bacteriology (known as International Bulletin of Bacteriological Nomenclature and Taxonomy from its inception in 1951 through 1965 and known as International Journal of Systematic and Evolutionary Microbiology [IJSEM] since 2000) [15]. Secondly, the Code required that all novel nomenclature be published in IJSEM. Provisions were additionally established for novel taxa to be published elsewhere and then later included on IJSEM validation lists. Finally, for valid publication, nomenclatural types were required to be designated (in part, through the deposit of type strains).

Two major revisions to the Code have ensued, with the most recent edition (now known as The International Code of Nomenclature of Prokaryotes) published in 2019 [16]. The reader is referred to chapters 1 and 2 of that resource for an introductory understanding of the general considerations and principles of the Code. Salient portions of these chapters are summarized here. The first and second general considerations state, "The progress of bacteriology can be furthered by a precise system of nomenclature accepted by the majority of bacteriologists of all nations" and "To achieve order in nomenclature, it is essential that scientific names be regulated by internationally accepted Rules" [16]. An additional consideration describes how the rules of nomenclature are not designed to determine the relatedness of taxa; they stand, instead, for "assessing the correctness of the names applied to defined taxa" and for "prescribing the procedures for creating and proposing new names."

Nine principles form the basis for the Code. For example, principle 1 [16] outlines essential factors in the maintenance of nomenclature: (i) stability of names, (ii) avoidance or rejection of names that may cause error or confusion, (iii) avoidance of useless creation of names, and (iv) the premise that freedom of taxonomic thought or action is not to be restricted via Code provisions. Principle 4 states that "the primary purpose of giving a name to a taxon is to supply a means of referring to it rather than to indicate the characters or the history of the 
taxon." Principle 6 declares that the "correct name of a taxon is based upon valid publication, legitimacy and priority of publication." Principle 7 adds that "a name of a taxon has no status under the Rules and no claim to recognition unless it is validly published." Finally, principle 9 declares that "the name of a taxon should not be changed without sufficient reason based either on further taxonomic studies or on the necessity of giving up a nomenclature that is contrary to the Rules of this Code."

\section{Novel/Revised Taxon Proposal and Publication}

As stated above, novel taxa pertinent to prokaryotic species must meet one of two requirements: (i) an original investigation published in IJSEM or (ii) a study published in an alternative journal with later inclusion on an IJSEM validation list. As an example, journals that published studies reporting novel Gram-negative taxa in 2018 and 2019 that may be relevant to the practice of clinical microbiology included Journal of Clinical Microbiology, Antonie Van Leeuwenhoek, Research in Microbiology, Applied and Environmental Microbiology, Standards in Genomic Sciences, New Microbes and New Infections, and Journal of Microbiology. Six times per year, IJSEM publishes papers entitled "List of New Names and New Combinations Previously Effectively, but Not Validly, Published." To be considered for inclusion on this validation list, authors must submit a copy of the published manuscript to IJSEM for confirmation that all elements necessary for valid publication have been met. In addition, type strains are to be deposited into two recognized culture collections in separate nations. Relative to this provision, journals that published papers regarding revised Gram-negative taxa in 2018 and 2019 include F1000Research, Genes, and Systematic and Applied Microbiology. Finally, IJSEM publishes two papers per year entitled "Notification of Changes in Taxonomic Opinion Previously Published Outside the IJSEM". These findings are simply offered as a service to bacteriology rather than statements of validly published or approved taxonomy.

Problems may be encountered when attempting to ascertain the relevance of novel or revised taxonomic designations for clinical microbiology practice. First, the vast majority of novel taxa are derived from environmental sources. Secondly, when isolates are known to be derived from humans, a number of publications (particularly those found in IJSEM) simply identify isolates as being derived from a specific specimen source (including sterile sites) but do not provide contextual clinical data. Therefore, in these scenarios (including a number of novel taxa derived from blood culture), the clinical significance of the taxa may best be interpreted as "not established." Additional studies and published case reports will be necessary to ultimately determine the clinical significance of several future novel taxa.

\section{Recent Conundrums in the Literature}

Additional examples are provided below to illustrate the somewhat confusing nature of bacterial taxonomy publication/revision, its notification to clinical microbiologists, and its relevance to clinical microbiology practice. Two major paradigm shifts have occurred within the past 4 years in what was formerly known as the family Enterobacteriaceae. First, the taxon Enterobacter aerogenes has been revised to Klebsiella aerogenes [17] as a result of the latter epithet becoming available due to a ruling of illegitimacy for the former Klebsiella mobilis. Clinical microbiologists have expressed reservations that this taxonomic revision may influence suboptimal antimicrobial therapy of infections caused by the former Enterobacter aerogenes, particularly when considering predicted antimicrobial susceptibility profiles of the genera Klebsiella and Enterobacter (cephamycin, first-generation cephem, and b-lactam/b-lactamase inhibitor combination agents) and the potential induction of AmpC chromosomal beta-lactamases associated with Enterobacter spp. [18]. A second paradigm shift involves reclassification of (former) Enterobacteriaceae genera, with the creation of six novel genera within the new order Enterobacterales ord. nov. Adeolu et al. [19] proposed these changes on the basis of genomic similarity and phylogenetic reconstructions of 1,548 core proteins, 53 ribosomal proteins, and four multilocus sequence 
analysis proteins. The current taxonomic status of the order Enterobacterales, according to updates by the online service List of Prokaryotic Names with Standing in Nomenclature (LPSN), is provided in Table 1. Noteworthy within the table are one family (Thorselliaceae) and eight genus

(including Calymmatobacterium and Plesiomonas) designations that were not investigated by Adeolu et al. On the other hand, these researchers

included Kosakonia spp., Lelliottia spp., Pluralibacter spp., Pseudocitrobacter spp., Rosenbergiella spp., and Siccibacter spp. in their investigation, though these genera are not included in the real-time LPSN database. Such discrepancies may provide an additional moving target for the clinical microbiologist in the attempt to ascertain clinically relevant shifts in prokaryotic taxonomy.

Table 1. Subdivisions of the order Enterobacterales according to the List of Prokaryotic Names with Standing in Nomenclature (http://www.bacterio.net/-classifphyla.html; accessed 20 December 2019)

\begin{tabular}{|l|l|}
\hline Family & Genus \\
\hline Budviciaceae & Budvicia (type genus) \\
& Leminorella \\
Pragia
\end{tabular}




\begin{tabular}{|c|c|}
\hline Family & Genus \\
\hline & Yokenella \\
\hline Erwiniaceae & $\begin{array}{l}\text { Buchnera } \\
\text { Erwinia (type genus) } \text { Mixta }^{\text {c }} \\
\text { Pantoea } \\
\text { Phaseolibacter } \\
\text { Tatumella } \\
\text { Wigglesworthia }\end{array}$ \\
\hline Hafniaceae & $\begin{array}{l}\text { Edwardsiella } \\
\text { Hafnia (type genus) } \\
\text { Obesumbacterium }\end{array}$ \\
\hline Morganellaceae & $\begin{array}{l}\text { Arsenophonus } \\
\text { Cosenzaea } \\
\text { Moellerella } \\
\text { Morganella (type genus) } \\
\text { Photorhabdus } \\
\text { Proteus } \\
\text { Providencia } \\
\text { Xenorhabdus }\end{array}$ \\
\hline Pectobacteriaceae & $\begin{array}{l}\text { Brenneria } \\
\text { Dickeya } \\
\text { Lonsdalea } \\
\text { Pectobacterium (type genus) } \\
\text { Sodalis }\end{array}$ \\
\hline Thorselliaceae $e^{\mathrm{d}}$ & $\begin{array}{l}\text { Coetzeea }^{\mathrm{a}} \\
\text { Thorsellia (type genus) }^{\mathrm{a}}\end{array}$ \\
\hline Yersiniaceae & $\begin{array}{l}\text { Chania } \\
\text { Ewingella } \\
\text { Rahnella } \\
\text { Rouxiella } \\
\text { Samsonia } \\
\text { Serratia } \\
\text { Yersinia (type genus) }\end{array}$ \\
\hline Unassigned & Phytobacter ${ }^{a}$ \\
\hline
\end{tabular}

${ }^{a}$ Genus not discussed in 2016 reclassification proposal of Adeolu et al. [19].

${ }^{b}$ Genus discussed in 2016 proposal of Adeolu et al. but not characterized as Enterobacterales in the List of Prokaryotic Names with Standing in Nomenclature.

${ }^{\mathrm{c}}$ Novel taxonomic designation published by IJSEM following the 2016 proposal of Adeolu et al.

${ }^{d}$ Family not discussed in 2016 proposal of Adeolu et al.

In 2014, Adeolu and Gupta [20] proposed the delineation of 14 Borrelia spp. into the novel genus Borreliella gen. nov. (Table 2). Eleven of these novel taxa have been validated by IJSEM [21, 22]. The original basis for this delineation was the demonstration of characteristic profiles of conserved molecular signature inserts/deletions 
(CSI) and conserved signature proteins (CSP) among Borrelia spp. that cause Lyme borreliosis and those that cause relapsing fever. These findings, when combined with ANI data, pathogenicity profiles, and arthropod vectors, resulted in the assignment of Lyme borreliosis spirochetes to the novel genus Borreliella, with retention of the genus Borrelia largely for relapsing fever spirochetes. Five novel Borrelia sp. taxa (Table 2), either derived from clinically ill patients or isolated from Ixodes sp. vectors, published in IJSEM following the report of Adeolu and Gupta [20] were not subject to reclassification. Controversy over the Borrelia sp./Borreliella sp. delineation has ensued in several rebuttals [23, 24, 25, 26, 27]. In one publication [23], a consortium of 27 scientists contended that CSI and CSP data were too preliminary in nature to support the reclassification. Furthermore, case reports describing overlapping clinical and epidemiologic data did not favor a strong delineation between the genera. In a second rebuttal [27], Margos et al. criticized the number of species (11 of 29 named and proposed species relative to relapsing fever; 11 of 22 Lyme borreliosis species) investigated in the original report, as well as the omission of other Borrelia spp. that may signify additional diversity within the genus Borrelia.

Table 2. Proposal for division of genus Borrelia, with establishment of Borreliella gen. nov. (based on 2014 publication of Adeolu and Gupta [20])

\begin{tabular}{|c|c|}
\hline Maintain Borrelia genus designation & Transfer to genus Borreliella gen. nov. \\
\hline $\begin{array}{l}\text { Borrelia anserina (type species) } \\
\text { Borrelia baltazardii } \text { Borrelia bissettiae }^{\text {a }} \\
\text { Borrelia brasiliensis } \\
\text { Borrelia californiensis }^{\text {a }} \\
\text { Borrelia caucasica }_{\text {Borrelia coriaceae }} \\
\text { Borrelia crocidurae } \\
\text { Borrelia dugesii } \\
\text { Borrelia duttonii } \\
\text { Borrelia graingeri } \\
\text { Borrelia harveyi } \\
\text { Borrelia hermsii } \\
\text { Borrelia hispanica } \\
\text { Borrelia lanei } \\
\text { Borrelia latyschewii } \\
\text { Borrelia mayonii } \\
\text { Borrelia mazzottii } \\
\text { Borrelia miyamotoi } \\
\text { Borrelia parkeri } \\
\text { Borrelia persica } \\
\text { Borrelia recurrentis } \\
\text { Borrelia theileri } \\
\text { Borrelia tillae } \\
\text { Borrelia turcica } \\
\text { Borrelia turicatae } \\
\text { Borrelia venezuelensis } \\
\text { Borrelia yangtzensis }^{\text {a }}\end{array}$ & 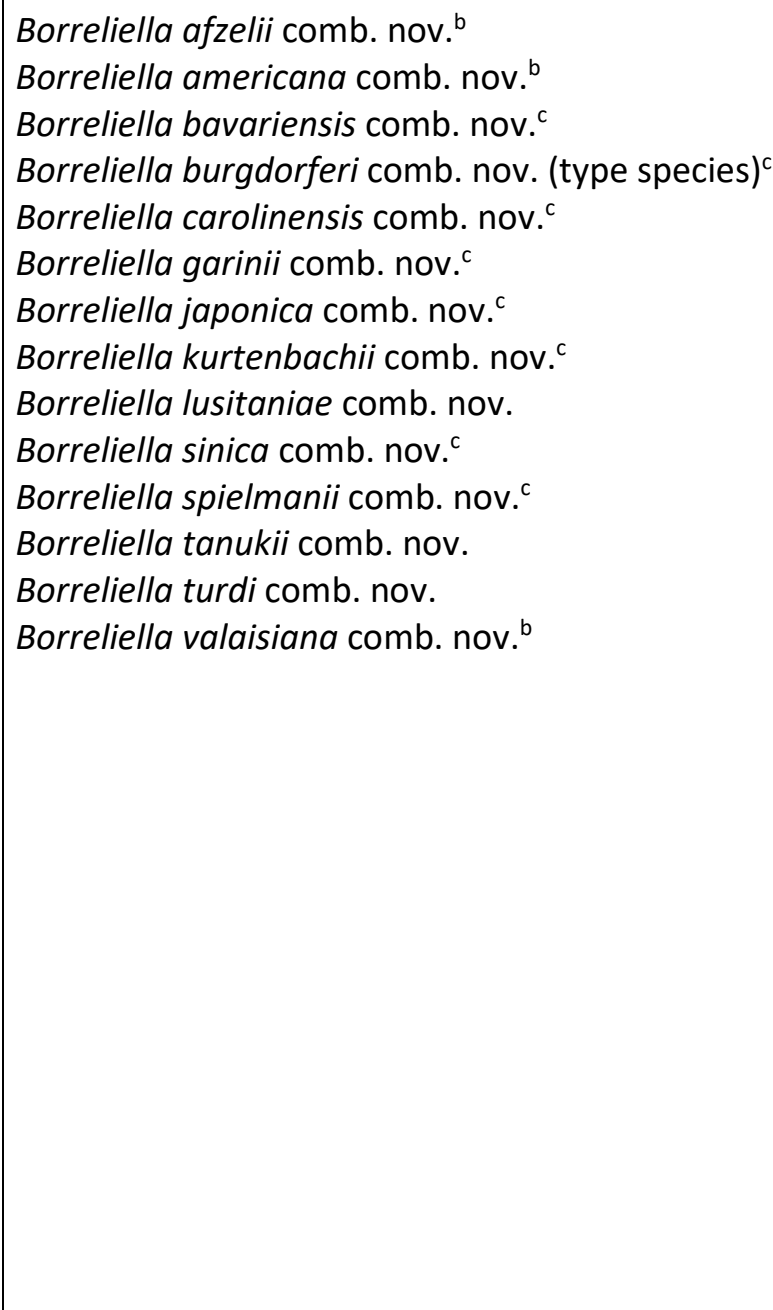 \\
\hline
\end{tabular}

${ }^{\text {a }}$ Novel taxonomic designation published in IJSEM following the 2014 reclassification proposal of Adeolu and Gupta [20].

${ }^{\mathrm{b}}$ Added per IJSEM validation list 182 in 2018 [21]. 
${ }^{c}$ Added per IJSEM validation list 163 in 2015 [22].

In a comprehensive report published in 2018, Gupta et al. [28] proposed the removal of several former members of the genus Mycoplasma and placement into the novel genera Malacoplasma gen. nov., Mesomycoplasma gen. nov., Metamycoplasma gen. nov., Mycoplasmoides gen. nov., and Mycoplasmopsis gen. nov. (Table 3). The basis for the delineation of the five novel genera ranged from four to seven characteristic CSI; 75\% of the 105 reassigned species have been validated by IJSEM [29, 30]. Type species within these genera include Malacoplasma iowae comb. nov., Mesomycoplasma hyopneumoniae comb. nov., Metamycoplasma hominis comb. nov., Mycoplasmoides pneumoniae comb. nov., and Mycoplasmopsis agalactiae comb. nov. The emerging sexually transmitted infection agent Mycoplasma genitalium has been reclassified as Mycoplasmoides genitalium comb. nov. The new genera are encompassed by the families Metamycoplasmataceae fam. nov. and Mycoplasmoidaceae fam. nov.

Table 3. Proposal for reclassification of selected members of the genus Mycoplasma, with establishment of the novel genera Malacoplasma gen. nov., Mesomycoplasma gen. nov., Metamycoplasma gen. nov., Mycoplasmoides gen. nov., and Mycoplasmopsis gen. nov. (based on 2018 publication of Gupta et al. [28])

\begin{tabular}{|c|c|}
\hline Novel genus designation & Included genus/species designations \\
\hline Malacoplasma gen. nov. & 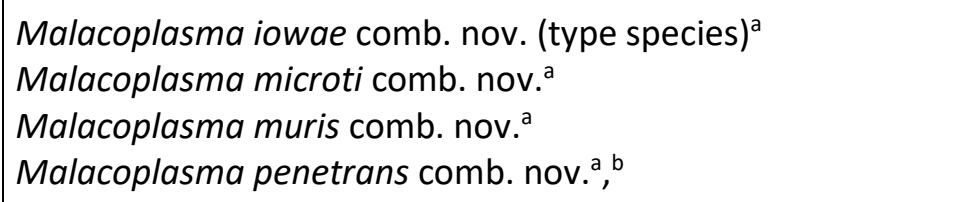 \\
\hline Mesomycoplasma gen. nov. & 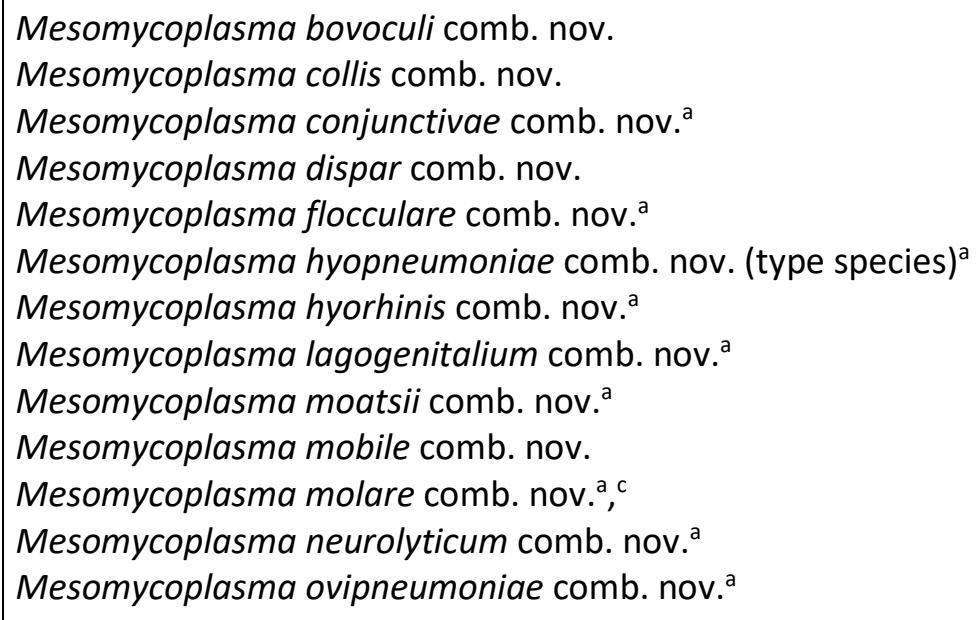 \\
\hline Metamycoplasma gen. nov. & 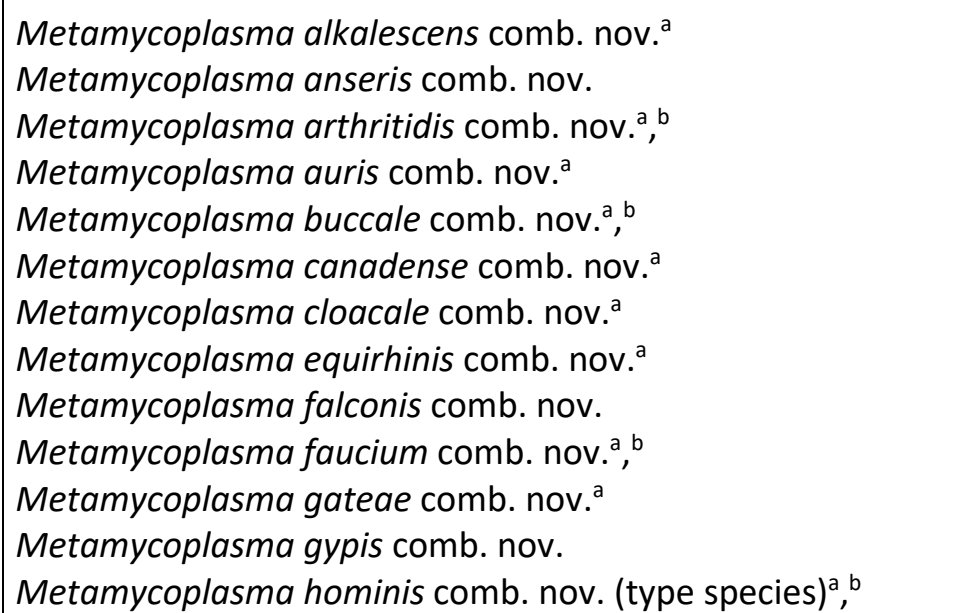 \\
\hline
\end{tabular}




\begin{tabular}{|c|c|}
\hline Novel genus designation & Included genus/species designations \\
\hline & $\begin{array}{l}\text { Metamycoplasma hyosynoviae comb. nov. }{ }^{\mathrm{a}} \\
\text { Metamycoplasma indiense comb. nov. } \\
\text { Metamycoplasma neophronis comb. nov. }{ }^{\mathrm{a}} \\
\text { Metamycoplasma orale comb. nov. }{ }^{\text {a }}{ }^{\mathrm{b}} \\
\text { Metamycoplasma phocae comb. nov. } \\
\text { Metamycoplasma phocicerebrale comb. nov. }{ }^{\text {a }} \\
\text { Metamycoplasma salivarium comb. nov. } .^{\mathrm{a}}{ }^{\mathrm{b}} \\
\text { Metamycoplasma spumans comb. nov. } \\
\text { Metamycoplasma sualvi comb. nov. }{ }^{\mathrm{a}} \\
\text { Metamycoplasma subdolum comb. nov. }\end{array}$ \\
\hline Mycoplasmoides gen. nov. & $\begin{array}{l}\text { Mycoplasmoides alvi comb. nov. }{ }^{\mathrm{a}} \\
\text { Mycoplasmoides amphoriforme comb. nov. } \\
\text { Mycoplasmoides cavipharyngis comb. nov. } \\
\text { Mycoplasmoides fastidiosum comb. nov. }{ }^{\mathrm{a}} \\
\text { Mycoplasmoides gallisepticum comb. nov. }{ }^{\mathrm{a}} \\
\text { Mycoplasmoides genitalium comb. nov. }{ }^{\mathrm{a}}{ }^{\mathrm{b}} \\
\text { Mycoplasmoides imitans comb. nov. } \\
\text { Mycoplasmoides pirum comb. nov. }{ }^{\mathrm{b}}, \\
\text { Mycoplasmoides pneumoniae comb. nov. (type species) }{ }^{\mathrm{a}}, \mathrm{b} \\
\text { Mycoplasmoides testudinis comb. nov. }\end{array}$ \\
\hline Mycoplasmopsis gen. nov. & 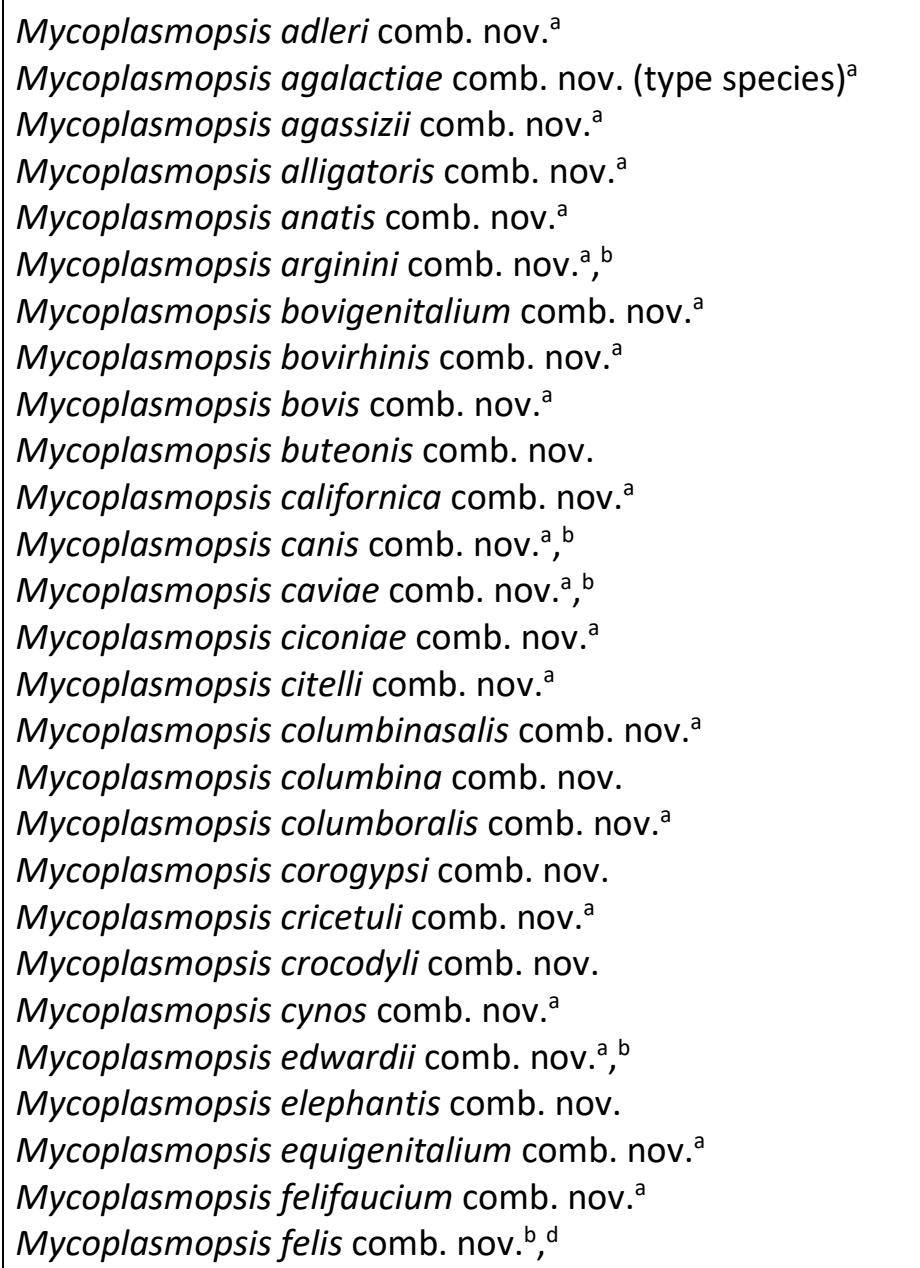 \\
\hline
\end{tabular}




\begin{tabular}{|c|c|}
\hline Novel genus designation & Included genus/species designations \\
\hline & 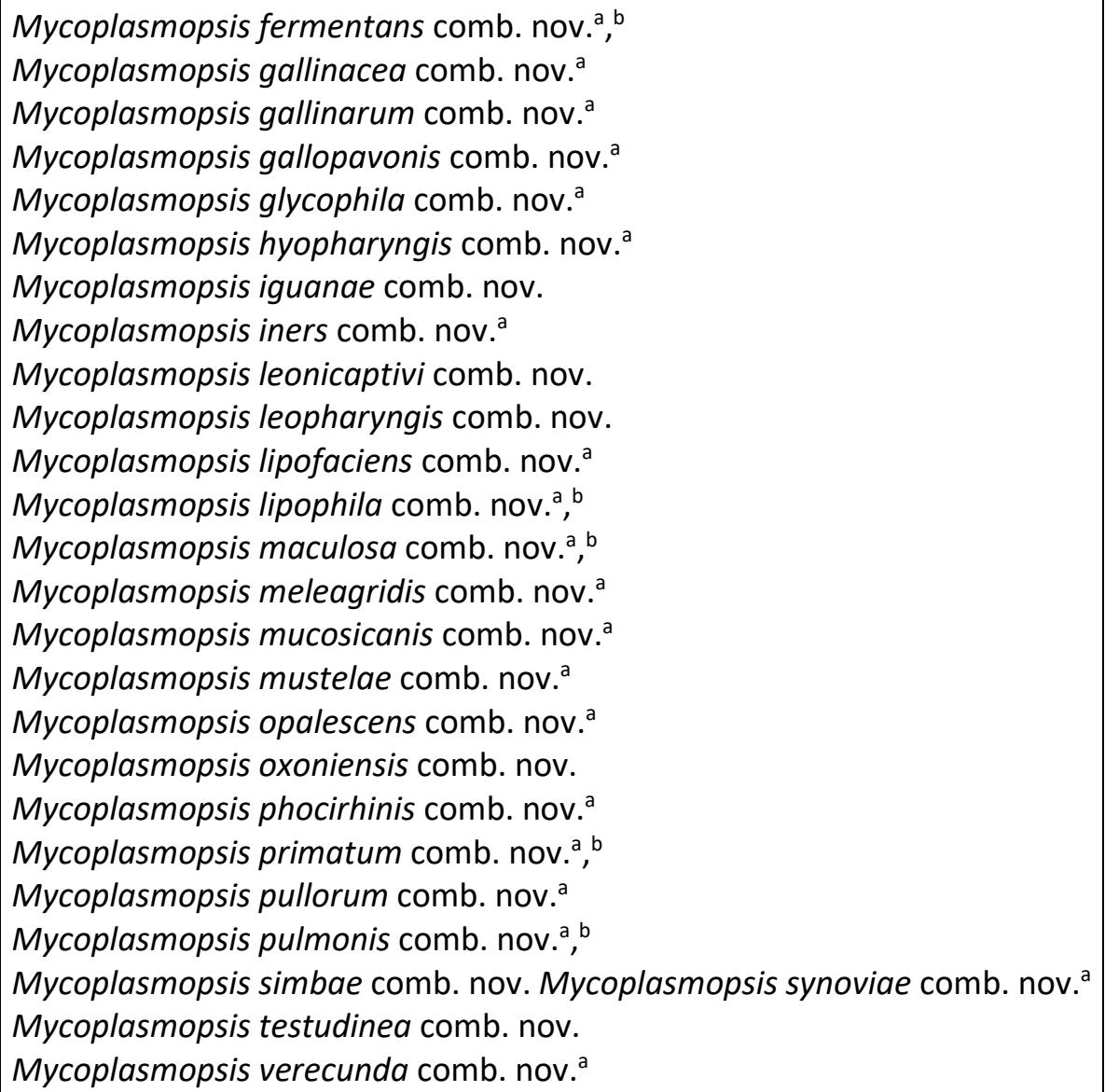 \\
\hline
\end{tabular}

${ }^{a}$ Added per IJSEM validation list 184 in 2018 [29].

${ }^{\mathrm{b}}$ Species detected from human clinical specimen.

c Originally published as Metamycoplasma molaris [28] but corrected by IJSEM [29].

${ }^{\mathrm{d}}$ Added per IJSEM validation list 184 in 2018 [30].

A group of 20 researchers, writing as members of the International Committee on Systematics of Prokaryotes' subcommittee on the taxonomy of Mollicutes, formally recommended rejection of these findings [31]. While this group actually viewed the core genome sequence investigations in a favorable light, and even as vindication of efforts in the field of mycoplasmatology, the researchers collectively characterized the nomenclature changes as an "unnecessary over-reach verging on taxonomic vandalism." The denunciation continued by citing several elements of the Code. Three tenets of principle 1 were invoked, namely, (i) aim for stability of names, (ii) avoid or reject the use of names that may cause error or confusion, and (iii) avoid the useless creation of names. Balish et al. [31] explained that the renaming of approximately 40 extant species (with the original nomenclature [basonyms] retaining standing in the nomenclature) would destabilize the nomenclature for microbiologists and regulatory agencies who use these names for applied and clinical purposes. Beyond the avoidance of names that may cause error or confusion, Balish et al. cited a chapter 3 rule that states, "A name may be placed on [the list of rejected names (nomina rejicienda)] for various reasons, including...a perilous name, i.e., a name whose application is likely to lead to accidents endangering health or life or both or of serious economic consequences." Referred taxa in this example include both human (M. genitalium, M. pneumoniae, and $M$. hominis) and veterinary ( $M$. agalactiae, $M$. bovis, and $M$. hyopneumoniae) pathogens, some of which are agents 
reportable to selected world and U.S. health agencies, which may have downstream treatment, import/export, and quarantine consequences.

Balish et al. [31] also suggested that numerous "comb. nov." designations were created by Gupta et al. [28] for the purpose of signifying a presumed history of taxon descent from a common ancestor (contravention of principle 4); numerous "comb. nov." designations did not possess sufficient justification for existence (a rationale that would have outweighed concerns regarding medical and agricultural utility; contravention of principle 9); numerous "comb. nov." designations were derived from analyses that would encounter difficulty with respect to future independent experimental replication (Code rule 28b); and, numerous "comb. nov." designations were based on selected diagnostic characters of the genomes that were used to alter current taxonomic restrictions (Code rule 37b). Moreover, Balish et al. even contended that at least two of the associated novel taxonomic designations contradict recommendation 6 of chapter 3, which states, "Avoid names of epithets that are very long or difficult to pronounce."

While revisions to the formerly constituted genera Borrelia and Mycoplasma have been challenged for largely scientific and practical reasons, respectively, the recent and perhaps overwhelming revision of the genus Mycobacterium proposed by Gupta et al. [32] may present additional problems for the clinical microbiologist. While mycobacteria of greater clinical significance, such as Mycobacterium tuberculosis (and its subspecies), Mycobacterium bovis (and its subspecies), Mycobacterium leprae, Mycobacterium kansasii, Mycobacterium avium (and its subspecies), Mycobacterium genavense, and Mycobacterium scrofulaceum, were not subject to this revision, 114 Mycobacterium spp. were reassigned to the novel genera Mycolicibacter gen. nov., Mycolicibacillus gen. nov., Mycobacteroides gen. nov., and Mycolicibacterium gen. nov (Table 4). $97 \%$ of these novel taxonomic designations have been validated by IJSEM [33]. Both the genera Mycobacteroides (type species Mycobacteroides abscessus comb. nov.) and Mycolicibacterium (type species Mycolicibacterium fortuitum comb. nov.) are comprised of rapidly growing mycobacteria. Gupta et al. [32] further noted that the two genera can be differentiated by 3-day arylsulfatase and nitrate reductase testing results (both positive for Mycolicibacterium spp.). The genera Mycolicibacter and Mycolicibacillus are comprised of organisms that require more than 7 days for growth; differentiating morphologic and biochemical traits were not provided. The major issue presented to the clinical microbiologist with respect to this genus reclassification is related largely to clinical relevance. Many of the species are saprophytic and are considered non-pathogenic to humans. Case reports regarding organism isolation (or nucleic acid detection) can be found in the medical literature for several of the species; however, in many of these scenarios, true clinical significance is difficult to establish. This calls into the question the necessity of laborious and persistent laboratory vigilance to recognize and assimilate such taxonomic revisions.

Table 4. Proposal for reclassification of selected members of genus Mycobacterium, with establishment of the novel genera Mycolicibacter gen. nov., Mycolicibacillus gen. nov., Mycobacteroides gen. nov., and Mycolibacterium gen. nov. (based on 2018 publication of Gupta [32])

\begin{tabular}{|c|c|}
\hline Novel genus designation & Included genus/species designations \\
\hline Mycolicibacter gen. nov. & 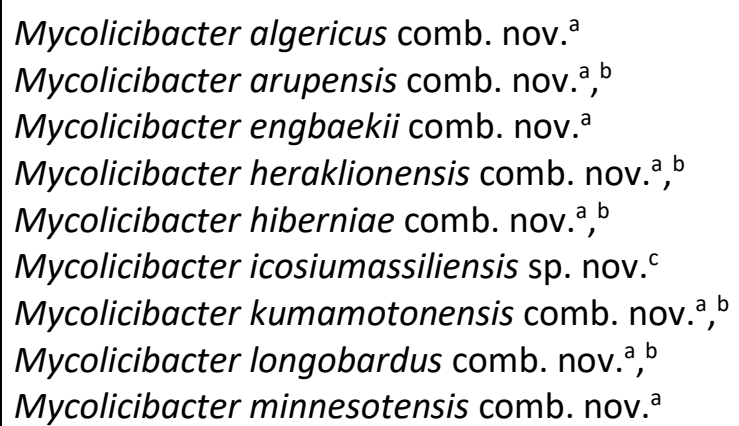 \\
\hline
\end{tabular}




\begin{tabular}{|c|c|}
\hline Novel genus designation & Included genus/species designations \\
\hline & $\begin{array}{l}\text { Mycolicibacter nonchromogenicus comb. nov. }{ }^{\mathrm{a}},{ }^{\mathrm{b}} \\
\text { Mycolicibacter paraterrae comb. nov. }{ }^{\mathrm{a}},{ }^{\mathrm{b}} \\
\text { Mycolicibacter senuensis comb. nov. }{ }^{a} \\
\text { Mycolicibacter sinensis sp. nov. }{ }^{\mathrm{c}} \\
\text { Mycolicibacter terrae comb. nov. (type species) }{ }^{\mathrm{a}},{ }^{\mathrm{b}} \\
\text { Mycolicibacter virginiensis comb. nov. }{ }^{\mathrm{b}}\end{array}$ \\
\hline Mycolicibacillus gen. nov. & $\begin{array}{l}\text { Mycolicibacillus koreensis comb. nov. }{ }^{\mathrm{a}, \mathrm{b}} \\
\text { Mycolicibacillus parakoreensis comb. nov. }{ }^{\mathrm{a}, \mathrm{b}} \\
\text { Mycolicibacillus trivialis comb. nov. (type species) }{ }^{\mathrm{a}, \mathrm{b}}\end{array}$ \\
\hline Mycobacteroides gen. nov. & 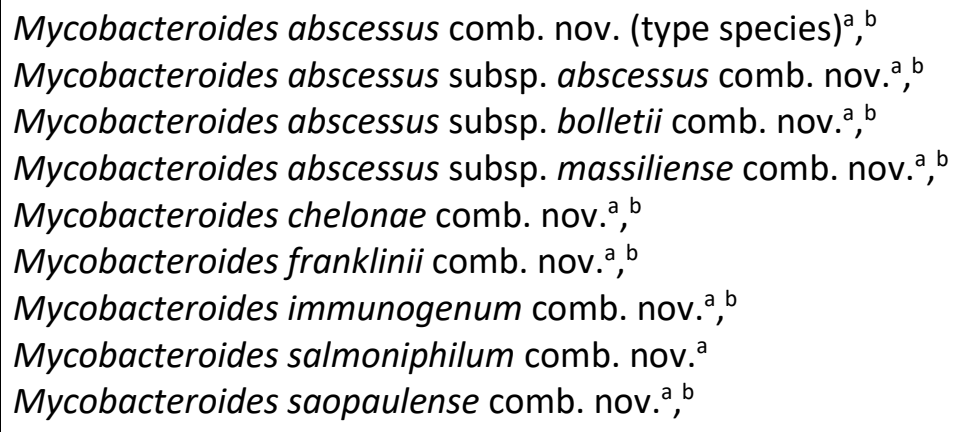 \\
\hline Mycolicibacterium gen. nov. & 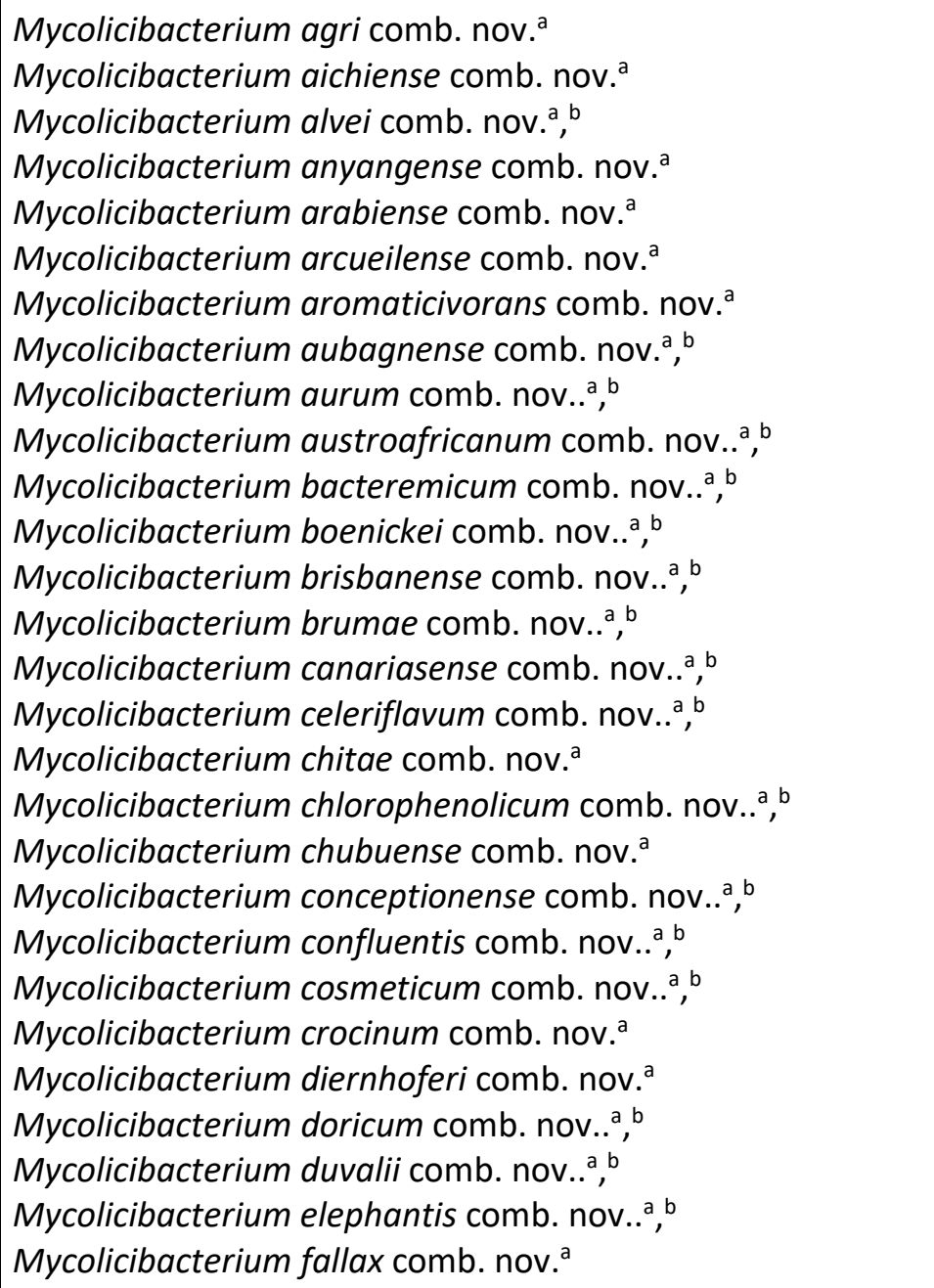 \\
\hline
\end{tabular}




\begin{tabular}{|c|c|}
\hline Novel genus designation & Included genus/species designations \\
\hline & $\begin{array}{l}\text { Mycolicibacterium farcinogenes comb. nov.. }{ }^{\mathrm{a}}, \mathrm{b} \\
\text { Mycolicibacterium flavescens comb. nov.. }{ }^{\mathrm{a}}, \\
\text { Mycolicibacterium fluoranthenivorans comb. nov.. }{ }^{\mathrm{a}},\end{array}$ \\
\hline Mycolicibacterium gen. nov. & 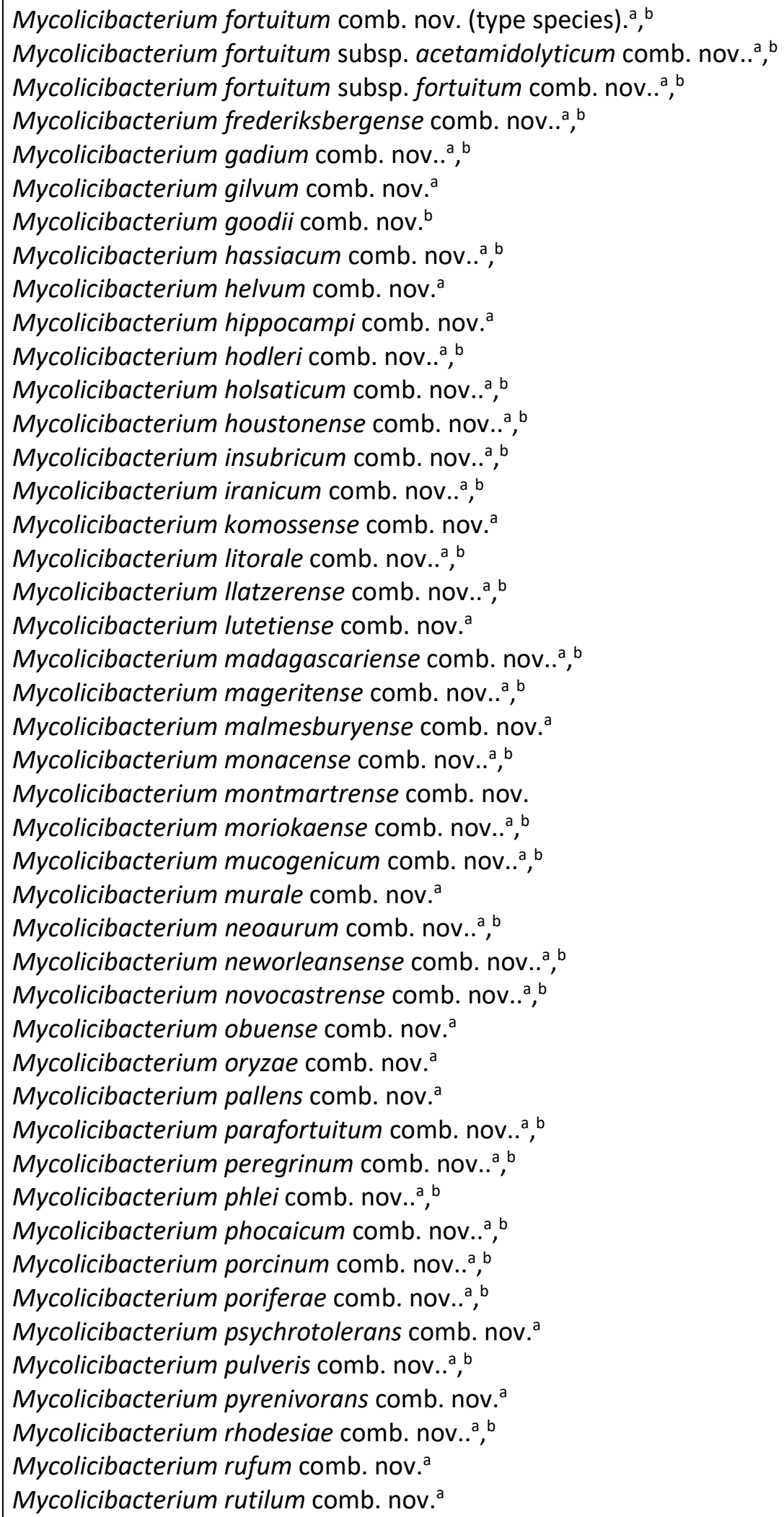 \\
\hline
\end{tabular}




\begin{tabular}{|c|c|}
\hline Novel genus designation & Included genus/species designations \\
\hline & 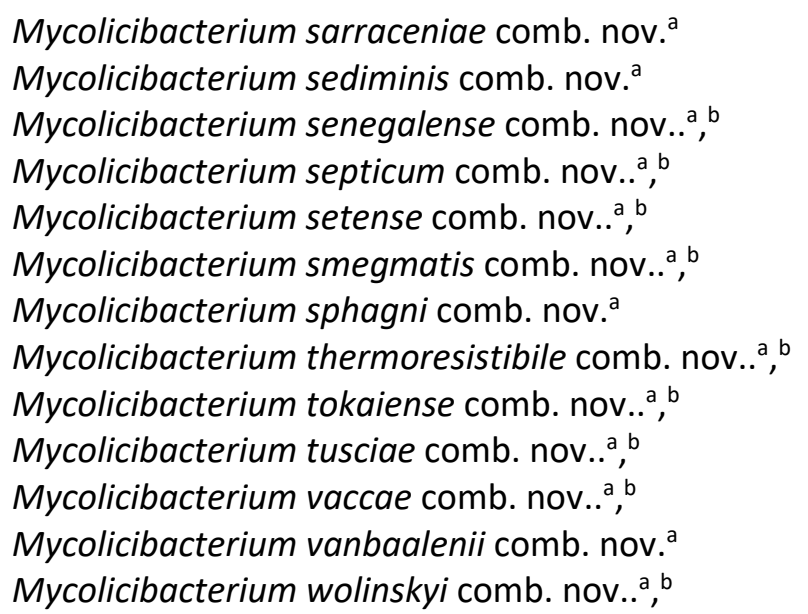 \\
\hline
\end{tabular}

a Added per IJSEM validation list 181 in 2018 [33].

${ }^{\mathrm{b}}$ Species detected from human clinical specimen.

${ }^{\mathrm{c}}$ Proposed new species of Mycolicibacter; designation not validated by IJSEM.

\section{What Should We Do Now?}

One of the major challenges for the clinical microbiologist in managing novel and changing prokaryotic taxonomy is simply becoming cognizant of the information. As mentioned above, publication of novel and revised taxa may occur through multiple outlets encompassing the fields of bacteriology, phylogenomics, and clinical microbiology. However, the reference standard for official recognition of bacterial taxa is IJSEM, through either original publication or inclusion on a validation list. The clinical microbiologist is encouraged to peruse this journal on a regular basis to ascertain taxonomic novelties that could affect daily practice. Recognizing potential time constraints of the laboratory director, supervisor, or bench technologist (particularly in light of the fact that the majority of bacterial taxonomy publications do not possess clinical relevance), at least two journals have committed to providing biennial compilations of microbial taxonomy revisions.

Diagnostic Microbiology and Infectious Diseases has published taxonomic updates on proposed classification and nomenclature changes for bacteria of medical importance since 2015 [34]. Journal of Clinical Microbiology has published microbial taxonomy updates in the fields of bacteriology [18], mycology, virology, parasitology, and mycobacteriology since 2017 [35]. Approaches to this task have slightly diverged in recent years. The latest Diagnostic Microbiology and Infectious Diseases report by Janda [34] restricts inclusion to novel taxa characterized by at least five strains (or taxa with substantial clinical correlation) and to taxonomic revisions having major clinical significance. Entries are sampled from a variety of journals with bacteriology and taxonomy focus, and not all the data are validated by IJSEM. Similarly, the Journal of Clinical Microbiology bacteriology compendia are based on isolates derived from human sources; however, these summaries are designed to cast a broader net with the thought that future case reports can validate the clinical significance of the taxa. In fact, clinical significance was later elucidated for Klebsiella michiganensis [36], a novel taxon that was listed in an initial Journal of Clinical Microbiology taxonomic summary. The majority of Journal of Clinical Microbiology entries are originally published in or subsequently validated by IJSEM.

In terms of laboratory adoption of taxonomic changes, Janda [37] outlined a multi-faceted approach, with focus on taxa characterized by several clinical isolates (optimally from sterile sources) or by strong clinical correlation. Beyond consistent peer-reviewed literature searches or reliance on biennial updates, it was recommended that laboratory adoption of novel taxa (particularly from non-IJSEM journals) not take place within the first year 
following publication (to allow ultimate validation by IJSEM). Taxonomic revisions can sometimes involve less stringency and may be adopted in a more timely fashion. A 1- to 2-year period in which the former genus designation is parenthetically incorporated into laboratory reports [Klebsiella (Enterobacter) aerogenes, as an example] has further been recommended prior to using the official taxonomic status.

\section{Summary}

A past publication [38] loosely compared the moving target of bacterial taxonomy to cautionary tales of the folklore genre. Our clinical partners encounter vast amounts of informatics and data on a daily basis. The means by which we microbiologists communicate these data (in clinically relevant fashion) may tremendously impact the care and even safety of our patients. Beyond this, the fields of therapeutics, diagnostics, pathogenesis, and epidemiology may also be influenced by nomenclature changes. In an effort to assist clinical and veterinary microbiology laboratories in managing and implementing taxonomic revisions in relevant fashion, CLSI has approved and appointed a document development committee charged with preparing a "Guideline for Implementation of Taxonomy Nomenclature Changes." This subcommittee is not designed to usurp the role of a taxonomist, but instead has the overarching goal of providing guidelines for the adoption and use of clinically relevant taxonomic changes. The document will be revised every 2 years, incorporating new scientific publications and feedback from users through the CLSI process; the document is anticipated to be published in 2022.

\section{Acknowledgments}

This commentary was not subject to influence from any funding agency in the public, commercial, or not-forprofit sectors. Richard B. (Tom) Thomson, Ph.D., D(ABMM) is acknowledged for critical review of the manuscript.

\section{References}

1. College of American Pathologists. Microbiology accreditation checklist. Northfield, IL, College of American Pathologists (2014)

2. TV Potts, JJ Zambon, RJ Genco. Reassignment of Actinobacillus actinomycetemcomitans to the genus Haemophilus as Haemophilus actinomycetemcomitans comb. Nov. Int J Syst Evol Microbiol, 35 (1985), pp. 337-341

3. N Nørskov-Lauritsen, M Kilian. Reclassification of Actinobacillus actinomycetemcomitans, Haemophilus aphrophilus, Haemophilus paraphrophilus, and Haemophilus segnis as Aggregatibacter actinomycetemcomitans gen. nov., comb. nov, Aggregatibacter aphrophilus comb. nov. and Aggregatibacter segnis comb. nov., and emended description of Aggregatibacter aphrophilus to include V factor-dependent and V factor-independent isolates. Int J Syst Evol Microbiol, 56 (2006), pp. 2135-2146

4. CLSI. Methods for antimicrobial dilution and disk susceptibility testing of infrequently isolated or fastidious bacteria. CLSI guideline M45. (3rd ed.), Wayne, PA, CLSI (2015)

5. P Kämpfer, H Matthews, SP Glaeser, K Martin, N Lodders, I Faye. Elizabethkingia anophelis sp. nov., isolated from the midgut of the mosquito Anopheles gambiae. Int J Syst Evol Microbiol, 61 (2001), pp. 2670-2675

6. T Frank, JC Gody, LB Nguyen, N Berthet, A Le Fleche-Mateos, P Bata, et al. First case of Elizabethkingia anophelis meningitis in the Central African Republic. Lancet, 381 (2013), p. 1876

7. MN Balm, S Salmon, R Jureen, C Teo, R Mahdi, T Seetoh, et al. Bad design, bad practices, bad bugs: frustrations in controlling an outbreak of Elizabethkingia meningoseptica in intensive care units. J Hosp Infect, 85 (2013), pp. 134-140

8. J Teo, SY Tan, M Tay, Y Ding, S Kjelleberg, M Givskov, et al. First case of $\boldsymbol{E}$. anophelis outbreak in an intensive-care unit. Lancet, 382 (2013), pp. 855-856 
9. SK Lau, AK Wu, JL Teng, H Tse, SO Curreem, SK Tsui, et al. Evidence for Elizabethkingia anophelis transmission from mother to infant, Hong Kong. Emerg Infect Dis, 21 (2015), pp. 232-241

10. SK Lau, WN Chow, CH Foo, SO Curreem, GC Lo, JL Teng, et al. Elizabethkingia anophelis bacteremia is associated with clinically significant infections and high mortality. Sci Rep, 6 (2016), p. 26045

11. RF Potter, CD Burnham, G Dantas. In silico analysis of Gardnerella genomospecies detected in the setting of bacterial vaginosis. Clin Chem, 65 (2019), pp. 1375-1387

12. M Vaneechoutte, A Guschin, L Van Simaey, Y Gansemans, F Van Nieuwerburgh, P Cools. Emended description of Gardnerella vaginalis and description of Gardnerella leopoldii sp. nov., Gardnerella piotii sp. nov. and Gardnerella swidsinskii sp. nov., with delineation of 13 genomic species within the genus Gardnerella. Int I Syst Evol Microbiol, 69 (2019), pp. 679-687

13. S Ciufo, S Kannan, S Sharma, A Badretdin, K Clark, S Turner, et al. Using average nucleotide identity to improve taxonomic assignments in prokaryotic genomes at the NCBI. Int J Syst Evol Microbiol, 68 (2018), pp. 2386-2392

14. SP Lapage, PHA Sneath, EF Lessel, VBD Skerman, HPR Seeliger, WA Clark (Eds.), International code of nomenclature of bacteria, 1975 revision, Washington, DC, American Society for Microbiology (1975)

15. VBD Skerman, V McGowan, PHA Sneath (Eds.), Approved lists of bacterial names, Int J Syst Bacteriol, 30 (1980), pp. 225-420

16. CT Parker, BJ Tindall, GM Garrity. International code of nomenclature of prokaryotes. Int J Syst Evol Microbiol, 69 (2019), pp. S1-S111

17. BJ Tindall, G Sutton, GM Garrity. Enterobacter aerogenes Hormaeche and Edwards 1960 (Approved Lists 1980) and Klebsiella mobilis Bascomb et al. 1971 (Approved Lists 1980) share the same nomenclatural type (ATCC 13048) on the Approved Lists and are homotypic synonyms, with consequences for the name Klebsiella mobilis Bascomb et al. 1971 (Approved Lists 1980). Int J Syst Evol Microbiol, 67 (2017), pp. 502-504

18. E Munson, KC Carroll. An update on the novel genera and species and revised taxonomic status of bacterial organisms described in 2016 and 2017. J Clin Microbiol, 57 (2019), pp. e01181-e01218

19. M Adeolu, S Alnajar, S Naushad, RS Gupta. Genome-based phylogeny and taxonomy of the 'Enterobacteriales': proposal for Enterobacterales ord. nov. divided into the families Enterobacteriaceae, Erwiniaceae fam. nov., Pectobacteriaceae fam. nov., Yersiniaceae fam. nov., Hafniaceae fam. nov., Morganellaceae fam. nov., and Budviciaceae fam. Nov. Int J Syst Evol Microbiol, 66 (2016), pp. 55755599

20. M Adeolu, RS Gupta. A phylogenomic and molecular marker based proposal for the division of the genus Borrelia into two genera: the emended genus Borrelia containing only the members of the relapsing fever Borrelia, and the genus Borreliella gen. nov. containing the members of the Lyme disease Borrelia (Borrelia burgdorferi sensu lato complex). Antonie Van Leeuwenhoek, 105 (2014), pp. 1049-1072

21. A Oren, GM Garrity. List of new names and new combinations previously effectively, but not validly, published. Int J Syst Evol Microbiol, 68 (2018), pp. 2130-2133

22. A Oren, GM Garrity. List of new names and new combinations previously effectively, but not validly, published. Int J Syst Evol Microbiol, 65 (2015), pp. 1105-1111

23. G Margos, D Marosevic, S Cutler, M Derdakova, M Diuk-Wasser, $S$ Emler, et al.. There is inadequate evidence to support the division of the genus Borrelia. Int J Syst Evol Microbiol, 67 (2017), pp. 1081-1084

24. AG Barbour, M Adeolu, RS Gupta. Division of the genus Borrelia into two genera (corresponding to Lyme disease and relapsing fever groups) reflects their genetic and phenotypic distinctiveness and will lead to a better understanding of these two groups of microbes (Margos et al. (2016) There is inadequate evidence to support the division of the genus Borrelia. Int. J. Syst. Evol. Microbiol. doi: 10.1099/ijsem.0.001717). Int J Syst Evol Microbiol, 67 (2017), pp. 2058-2067 
25. G Margos, A Gofton, D Wibberg, A Dangel, D Marosevic, SM Loh, et al. The genus Borrelia reloaded. PLoS One, 13 (2018), p. e0208432

26. RS Gupta. Distinction between Borrelia and Borreliella is more robustly supported by molecular and phenotypic characteristics than all other neighbouring prokaryotic genera: response to Margos' et al. "The genus Borrelia reloaded" (PLoS ONE 13(12): e0208432). PLoS One, 14 (2019), p. e0221397

27. G Margos, V Fingerle, C Oskam, B Stevenson, A Gofton. Comment on: Gupta, 2019, distinction between Borrelia and Borreliella is more robustly supported by molecular and phenotypic characteristics than all other neighbouring prokaryotic genera: response to Margos' et al. "The genus Borrelia reloaded" (PLoS One 13(12): e0208432). PLoS One 14(8):e0221397. Ticks Tick Borne Dis (2019) doi: 10.1016/j.ttbdis.2019.101320 [Epub ahead of print].

28. RS Gupta, S Sawnani, M Adeolu, S Alnajar, A Oren. Phylogenetic framework for the phylum Tenericutes based on genome sequence data: proposal for the creation of a new order Mycoplasmpoidales ord. nov., containing two new families Mycoplasmoidaceae fam. nov. and Metamycoplasmataceae fam. nov. harbouring Eperythrozoon, Ureaplasma and five novel genera. Antonie Van Leeuwenhoek, 111 (2018), pp. $1583-1630$

29. A Oren, GM Garrity. List of new names and new combinations previously effectively, but not validly, published. Int J Syst Evol Microbiol, 68 (2018), pp. 3379-3393

30. A Oren, GM Garrity. List of new names and new combinations previously effectively, but not validly, published. Int J Syst Evol Microbiol, 69 (2019), pp. 597-599

31. M Balish, A Bertaccini, A Blanchard, D Brown, G Browning, V Chalker, et al. Recommended rejection of the names Malacoplasma gen. nov., Mesomycoplasma gen. nov., Metamycoplasma gen. nov., Metamycoplasmataceae fam. nov., Mycoplasmoidaceae fam. nov., Mycoplasmoidales ord. nov., Mycoplasmoides gen. nov, Mycoplasmopsis gen. nov. [Gupta, Sawnani, Adeolu, Alnajar and Oren 2018] and all proposed species comb. nov. placed therein. Int J Syst Evol Microbiol, 69 (2019), pp. 36503653

32. RS Gupta, B Lo, J Son. Phylogenomics and comparative genomic studies robustly support division of the genus Mycobacterium into an emended genus Mycobacterium and four novel genera. Front Microbiol, 9 (2018), p. 67

33. A Oren, GM Garrity. List of new names and new combinations previously effectively, but not validly, published. Int J Syst Evol Microbiol, 68 (2018), pp. 1411-1417

34. JM Janda. Proposed nomenclature or classification changes for bacteria of medical importance: taxonomic update 4. Diagn Microbiol Infect Dis, 94 (2019), pp. 205-208

35. CS Kraft, AJ McAdam, KC Carroll. A rose by any other name: practical updates on microbial nomenclature for clinical microbiology. J Clin Microbiol, 55 (2017), pp. 3-4

36. B Zheng, H Xu, X Yu, T Lv, X Jiang, H Cheng, et al. Identification and genomic characterization of a KPC-2-, NDM-1- and NDM-5-producing Klebsiella michiganensis isolate. J Antimicrob Chemother, 73 (2018), pp. 536-538

37. JM Janda. Clinical decisions: how relevant is modern bacterial taxonomy for clinical microbiologists? Clin Microbiol Newsl, 40 (2018), pp. 51-57

38. E Munson, KC Carroll. Whither extensive genomic-based microbial taxonomic revision? Clin Chem, 65 (2019), pp. 1343-1345 